\title{
Masonería y educación en la España contemporánea. Entre la tolerancia y el dogmatismo
}

\section{Freemasonry and Education in Contemporary Spain. Between Tolerance and Dogmatism}

\begin{abstract}
José Ignacio Cruz Orozco
Doctor en filosofía y ciencias de la educación por la Universidad de Valencia (España) y profesor titular en dicha universidad. Miembro fundador del Centro de Estudios Históricos de la Masonería Española (CEHME) y en la actualidad vicepresidente de su junta directiva. Correo electrónico: jose.i.cruz@uv.es
\end{abstract}

DOI: http://dx.doi.org/10.15517/rehmlac.v9i1.28630

Fecha de recibido: 10 de marzo de 2017 - Fecha de aceptación: 15 de abril de 2017

\section{Palabras clave}

Sistema educativo español; talleres de formación masónicos; España; historia contemporánea.

\section{Keywords}

Spanish Educational System; Masonic Training Workshops; Spain; Contemporary History.

\begin{abstract}
Resumen
En este trabajo vamos a centrarnos casi en exclusiva en las iniciativas planteadas por diversas entidades masónicas, ya sean potencias, logias regionales o talleres, más que en personas exponiendo solamente algunas de las experiencias más relevantes y que ejemplifican mejor las intervenciones y actuaciones de la masonería española en relación con los enfoques descritos. La visibilidad que han alcanzado otras parcelas e interpretaciones del comportamiento, de los masones en particular y de las iniciativas de la masonería como institución, no nos deben ocultar la faceta desarrollada en torno a la educación. ¿Qué importancia tuvo el proceso formativo llevado a cabo en los talleres masónicos a sus integrantes? ¿Qué lugar ocupó la masonería en el desarrollo educativo español?
\end{abstract}

\begin{abstract}
In this paper, we mainly focus mainly on initiatives that were proposed by several Masonic bodies, which are obediences, regional lodges or workshops, rather than only on people sharing their most relevant experiences, and thus present us with a wide range of interventions and deeds of Spain's Freemasonry. We must not allow the visibility Freemasonry has obtained in other areas and behaviors of freemasons as individuals hide the brethren's developments in education. How important was the learning process within the Masonic lodges? What role did Freemasonry play within Spain's educational development?
\end{abstract}




\section{Introducción}

A la hora de estudiar el comportamiento de las entidades masónicas españolas en relación con el ámbito educativo vamos a plantear en este trabajo dos enfoques bien diferenciados. En primer término, consideraremos a la educación desde la perspectiva interna de la propia institución, vinculada específicamente a los procesos de formación que los afiliados siguen dentro de las logias. Se trata de un ámbito poco trabajado, complicado de analizar, pero de cuya importancia no puede dudarse ${ }^{1}$.

Por otra parte, si hablamos de masonería y educación en el contexto histórico español, también debemos analizar las iniciativas que esta ha llevado a cabo para influir en la orientación de la política educativa del país. Dentro de este ámbito diferenciaremos, a su vez, dos parcelas. Por un lado, las iniciativas ubicadas en el ámbito de las ideas. Esto es, los planteamientos y formulaciones que la orden fue realizando a lo largo de los años sobre cómo debía ser las características más relevantes de la educación española. Sería lo que hemos convenido en denominar: declaraciones programáticas. Junto a ellas, y como complemento, situaremos las iniciativas concretas llevadas a cabo por entidades masónicas para fundar o apoyar una determinada institución o iniciativa educativas. En este caso, se trataría de intervenciones específicas con las cuales concretar en la práctica y dentro de la estructura del sistema educativo el ideario proclamado.

Clarificado mínimamente el campo de estudio, debemos efectuar una última precisión más. En este trabajo vamos a centrarnos casi en exclusiva en las iniciativas planteadas por diversas entidades masónicas, ya sean potencias, logias regionales o talleres, más que en personas o personajes concretos. Pienso que en el primer caso nos movemos en terreno mucho más seguro, ya que, sea la propuesta que sea, lleva la firma clara y precisa de una entidad masónica. En cambio, cuando la iniciativa se atribuye a un personaje público en concreto, resulta mucho más complicado atribuir con certeza si la orientación ideológica proviene del ámbito masónico, del político, de cualquier otra identidad de la persona en cuestión, o de una amalgama de todos ellos imposible de discernir a ciencia cierta.

Para finalizar estas cuestiones más generales, solo nos queda por añadir en este apartado preliminar, que vamos a limitarnos a ir exponiendo solamente algunas de las experiencias más relevantes y que ejemplifican mejor las intervenciones y actuaciones de la masonería española en relación con los enfoques descritos. La limitación de espacio del que

\footnotetext{
${ }^{1}$ Un indicador del desequilibrio entre la importancia de los procesos masónicos de formación interna y los escasísimos estudios que se han efectuado sobre ellos, es que apenas podemos localizar referencias a esta cuestión en las actas de los XII Symposia Internacionales de Historia de la masonería Española, un compendio de referencia sobre las investigaciones académicas acerca la historia de la masonería. José Antonio Ferrer Benimeli coord., Índices de actas, de los Symposia Internacionales de Historia de la masonería Española (Zaragoza: Centro de Estudios Históricos de la Masonería Española, 2009).
} 
disponemos nos impide realizar una enumeración más amplia. Pese a ello, pensamos que los casos presentados resultan lo suficientemente significativos como para poder extraer algunas conclusiones de entidad acerca de cuáles fueron las características más destacadas de la actuación de la masonería española en relación con la educación.

\section{La educación como un elemento interno}

Como ya se indicó, se trata de un ámbito escasamente estudiado y que no se deja delimitar con facilidad. La visibilidad que han alcanzado otras parcelas e interpretaciones del comportamiento, de los masones en particular y de las iniciativas de la masonería como institución, no nos deben ocultar esta otra faceta mucho menos vistosa, pero de indudable trascendencia, al menos para algunos masones. El punto de partida sería el siguiente planteamiento: ¿Qué importancia tuvo el proceso formativo llevado a cabo en los talleres masónicos a sus integrantes? Se trata de un aspecto relevante, definido en los textos masónicos como la transmisión de conocimientos, siempre con la finalidad de buscar de la manera más efectiva posible el progreso de la humanidad.

Un claro indicador de la importancia de esta faceta de la actividad masónica lo encontramos en la Declaración de Principios del Grande Oriente Español, vigente en el primer tercio del siglo pasado. Allí se señalaba, en un lugar tan preeminente como el segundo párrafo, que: "Su misión (la del GOE) es la de estudiar desinteresadamente todos los problemas que conciernen a la vida de la humanidad para hacer su vida más fraternal". Y añadía a continuación que el masón que pasara a formar parte de sus cuadros lógicos debería ser "ilustrado, moral y libre"... "Ilustrado para que pueda por sí mismo, distinguir entre la verdad y el error y concurrir determinantemente a la obra del progreso que persigue la Historia, siempre reservada a las clases más instruidas"2.

Dentro de este enfoque, debemos detenernos en un testimonio concreto: el de Fernando Valera. Un político de la II República, hoy bastante olvidado, que aunque nació el Madroñera, Cáceres, vivió y mantuvo una intensa relación con Valencia. Fernando Valera fue un personaje sumamente interesante y polifacético. Concejal en el Ayuntamiento de Valencia en 1931, diputado en las constituyentes de ese mismo año por el Partido Republicano Radical Socialista, director general y subsecretario en diversas carteras. Fue un auténtico republicano toda su vida. También cuando vinieron mal dadas, ya que fue una de las cabezas destacadas, sino la que más, del reducido núcleo de exiliados empeñados en mantener la legitimidad republicana por medio del muy testimonial gobierno de la República española en el exilio. Un gobierno ubicado en París, pero sin territorio, ni administración, cuya ciudadanía englobaba solo a un reducido puñado de fieles idealistas

\footnotetext{
${ }^{2}$ Grande Oriente Español, Constitución del Grande Oriente Español (Sevilla: Tipografía Minerva, s.a.), 5.
} 
entre los exiliados de la guerra civil, desperdigados por los países de la vieja Europa y las repúblicas americanas.

El aspecto que nos interesa resaltar de Fernando Valera es que, además de su identidad política, la masonería ocupó un lugar destacado en su trayectoria vital. Se inició en 1924 en la logia valenciana Tyris y fue ascendiendo en la escala hasta ingresar en 1944 en el Supremo Consejo del Grado 33. En el aspecto que nos incumbe, resulta especialmente interesante la experiencia formativa que siguió a partir del momento de su iniciación. En un documento inédito, describía de este modo una de las motivaciones más destacadas que le llevó a iniciarse:

Luego, al estudiar filosofía esotérica en mi juventud, tuve noticia más circunstanciada de lo que era la moderna masonería, así como de sus raíces milenarias en los misterios iniciáticos de la antigüedad, en la Escuela pitagórica de Crotona, en la neoplatónica de Alejandría, en la propia Iglesia esotérica de los primeros cristianos, etc. etc." ${ }^{3}$.

Afirmaciones en esa misma línea de reflexión se pueden localizar en una conferencia pronunciada en la Gran Logia de Argentina en 1962, en la que insistió en la utilidad de la simbología y el rito ${ }^{4}$. No resulta habitual encontrar ese tipo de referencias. Fernando Valera resulta un ejemplo incuestionable de que, en el seno de la masonería española contemporánea, existió un sector para quienes esta fue también un señalado espacio de estudio, reflexión y de trasmisión de saberes, que podríamos englobar bajo la etiqueta de heterodoxos. Una escuela de formación en suma, tal como se proclamaba en la Declaración de Principios antes mencionada.

\section{Declaraciones ideológicas}

El ámbito escolar ha sido, sin ningún género de dudas, un espacio especialmente significativo en la intensa pugna que ha enfrentado a las diversas fuerzas sociales, ideológicas y políticas de la España contemporánea. Las diversas interpretaciones sobre el

\footnotetext{
${ }^{3}$ Fernando Valera, “Apuntes para contestar a un cuestionario de don Aquilino González, en preparación de un trabajo periodístico sobre la masonería en España”, Documento mecanografiado. Archivo particular. Sobre la figura de Fernando Valera puede consultarse, Esteban Cortijo, "Fernando Valera Aparicio: Teósofo, masón y republicano" en La masonería en la España del siglo XX, coord. Ferrer Benimeli (Toledo: Universidad de Castilla-La Mancha y Cortes de Castilla-La Mancha, 1996), vol. II, 287-308.

${ }^{4}$ Valera, Misión de la Francmasonería en la reconstrucción de la Democracia Española. Conferencia pronunciada en la Gran Logia de la Argentina (Buenos Aires, Símbolo, 1962), 12. Resulta de interés señalar que en España en el primer tercio del siglo XX, la obediencia de la Gran Logia Española, -precisamente en la que se inició Fernando Valera, aunque a partir de 1931 se situó dentro de las filas del Grande Oriente Español- insistió especialmente en la importancia de los símbolos y el ritual. José Ignacio Cruz, "Masonería española en el XX. Entre el mito y la realidad", en Masonería e Ilustración. Del siglo de las luces a la actualidad, ed. José Ignacio Cruz (Valencia: Publicacions de la Universitat de València, 2011), 131-150.
} 
significado, alcance y limitaciones que presentan conceptos tales como el derecho a la educación y la libertad de enseñanza, desataron intensos debates en la España de finales del XIX y del primer tercio del XX, cuyos ecos llegan hasta nuestros días.

En aquellos años, además, tales debates se enmarcaban en un panorama con problemas educativos de enorme trascendencia, entre los cuales destacaban unas tasas de escolarización muy bajas. En 1920 la mitad de los niños españoles de 10 años no sabían leer ni escribir, y el bachillerato, la actual educación secundaria obligatoria en su primer tramo de cuatro años, constituía un muy reducido reducto destinado exclusivamente a hijos de la burguesía ${ }^{5}$. A esos significativos problemas cuantitativos se sumaban los ideológicos. A grandes rasgos, podemos señalar que durante la restauración y la dictadura de Primo de Rivera, la Iglesia católica consiguió mantener un rol especialmente destacado en la enseñanza. No sólo pudo desarrollar sin demasiados controles ni cortapisas sus propios centros docentes, sino que mantuvo influencias destacadas en la enseñanza pública, llegando a considerar a la educación como un espacio propio que debía estar regido de acuerdo con sus intereses. Esto significó que los grupos opuestos al régimen criticaran, no solo la pasividad gubernamental, sino también los privilegios eclesiásticos.

Lo primero que debemos señalar a la hora de abordar el papel desempeñado por la masonería en este terreno concreto es que, de acuerdo con lo expresado por el profesor Ferrer Benimeli, la enseñanza se convirtió desde finales del XIX en un terreno de enfrentamiento entre la masonería y la Iglesia católica ${ }^{6}$. Bajo tal prisma se sitúan la inmensa mayoría de las iniciativas de logias y orientes. Apenas podemos encontrar un puñado de propuestas fuera de este parámetro y que apunten a cuestiones de índole más técnico-pedagógica. Estas últimas, siempre con planteamientos muy genéricos para mejorar la dotación de alguna escuela, otorgar el apoyo a una metodología innovadora y poco más. ${ }^{7}$

Dejando aparte ese reducido grupo de propuestas, la mayoría se centran en criticar el papel de la Iglesia católica en la escuela. En un debate en el cual las mutuas acusaciones, de anticlericalismo y laicismo por parte de los sectores confesionales y de vaticanismo, clericalismo o jesuitismo por el masónico, se sucedieron sin descanso. Este es un aspecto en el que coinciden la gran mayoría de especialistas que han tratado esa cuestión, insistiendo en el privilegiado lugar que las cuestiones relativas al laicismo escolar han ocupado en el universo ideológico de la masonería española. Ampliando el ámbito de referencia y

\footnotetext{
${ }^{5}$ Narciso de Gabriel, “Alfabetización y escolarización en España (1887-1950)", Revista de Educación 314 (1997): 217-243; M. Gloria Espigado Tocino, "El analfabetismo en España. Un estudio a través del censo de población de 1877", Trocadero: Revista de historia moderna y contemporánea 2 (1990): 173-192; Antonio Viñao, Escuela para todos. Educación y modernidad en la España del siglo XX (Madrid: Marcial Pons. 2004); y Cruz, "Los institutos de segunda enseñanza en España. Datos sobre su implantación (1835-1936)", Educatio Siglo XXI 30, no. 1 (2012): 233-252.

${ }^{6}$ Ferrer Benimeli, La masonería española (Madrid: Itsmo, 1996), 129.

${ }^{7}$ Cruz, "Lo que nos contaron, lo que sabemos y lo que nos queda por conocer. Masonería y educación en la España contemporánea", en La masonería española en el 2000. Una revisión histórica, ed. Ferrer Benimeli (Zaragoza: Centro de Estudios Históricos de la Masonería Española, 2001), Vol. I, 13-23.
} 
empleando la terminología de la época, resulta evidente que la masonería ocupó un lugar destacado dentro del movimiento anticlerical español de aquellos años y que los planteamientos contubernistas orientaron en bloque la posición de la iglesia española y de los sectores confesionales.

Aunque hubo otros discursos un poco más moderados en los cuales se dejaba entrever el tradicional concepto masónico de tolerancia, lo que fundamentalmente se debatieron y aprobaron en los talleres masónicos fueron proclamas redactadas en un todo radical y con un registro especialmente dogmático. Pensamos que no se puede interpretar de otro modo, por ejemplo, la llamada realizada en 1887 por el venerable Díaz y Pérez a combatir “.... sin tregua ni descanso toda manifestación clerical y jesuítica". Si nos atenemos a la reflexión publicada en 1933 en el portavoz oficial del Grande Oriente Español por el aprendiz Herrero Palahí, esas propuestas permanecieron durante décadas ocupando un lugar muy destacado en el imaginario masónico, sin variar demasiado. Casi medio siglo después el Boletín de la principal potencia masónica española alentaba otra vez a acabar "...para siempre con ese monstruoso y tenebroso poder jesuítico opresor de la sociedad" $"$.

Desde el otro extremo de la polémica, los sectores confesionales culparon en reiteradas ocasiones a la masonería de casi todos los males que sufrió nuestro país. Uno de los autores contubernistas más representativos fue el sacerdote catalán Juan Tusquets, el cual hizo gala de sus firmes convicciones antimasónicas en multitud de escritos y declaraciones ${ }^{9}$. Dada la temática en la que nos centramos, puede servir de ejemplo una intervención suya en una de las semanas pedagógicas organizadas por la Federación de Amigos de la Enseñanza (FAE), entidad que representaba los intereses en el ámbito educativo de las congregaciones religiosas. La participación de Tusquets tuvo lugar en 1933- resulta coetánea de la citada en el párrafo anterior por Herrero Palahí y ambas visualizan muy bien en grado de enfrentamiento existente- en los azarosos días de la II República, cuanto el gobierno estaba a punto de aprobar serias limitaciones a los colegios confesionales. La valoración que efectuaba Tusquets resultaba contundente: "La masonería se puede decir que es conjunto de individuos entre si compenetrados para combatir la Religión. Podemos decir que la masonería en el terreno técnico es el fanatismo de la irreligión, el fanatismo de la irreligiosidad". Y en el caso concreto de la política educativa de aquellos momentos, aplicaba el principio general ya enunciado afirmando: “... la masonería tiene la culpa de la actual persecución sectaria en el terreno pedagógico", ${ }^{\text {. }}$.

\footnotetext{
${ }^{8}$ Cruz, Masonería y educación en la II República Española (Alicante: Instituto de Cultura "Juan Gil Albert", 1993), 148-153.

${ }^{9}$ Jordi Canal, "Las campañas antisectarias de Juan Tusquets (1827-1939): Una aproximación a los orígenes del contubernio judeo-masónico-comunista en España", en La masonería en la España del siglo XX, vol. II, 1193-1214.

10 Juan, Tusquets, "Influencia sectaria en las escuelas", en Cuestiones actuales de Pedagogía (Madrid: Gráfica HALAR, 1934), vol. II, 207-218. Cabe señalar que Tusquets realizaba una interpretación algo
} 


\section{Iniciativas educativas concretas}

Pasando ahora al terreno de las intervenciones más concretas, algunas de las más interesantes y significativas llevadas a cabo por la masonería española en el ámbito pedagógico, tuvieron como objetivo la creación y sostenimiento de escuelas laicas. De acuerdo con los datos que se conocen hasta ahora, gracias a las diversas investigaciones que han ido apareciendo en los últimos años, podemos realizar un balance relativamente preciso.

Como ya se indicó, una de las peculiaridades del sistema educativo español durante muchas décadas, consistió en la escasez de inversión pública. En consecuencia, existían pocas escuelas públicas, los maestros estaban mal pagados, peor considerados, y los presupuestos de instrucción pública resultaban especialmente escasos. Con tal panorama, el cual se perpetuaba año tras año, la iniciativa privada trató de suplir algo esas graves carencias, creando un número relativamente elevado de escuelas y centros docentes.

Durante la restauración Alfonsina los distintos grupos antimonárquicos, aprovechando el reconocimiento formal de algunos derechos típicos del sistema liberal, fueron tejiendo una red de escuelas con una orientación ideológica diferente. En suma, se trataba básicamente de fomentar las ideas laicistas y generar una alternativa a los colegios confesionales que, dada la orientación ideológica y la base social del régimen, gozaban de importantes apoyos sociales y gubernamentales.

Una de las actividades más destacadas de los masones en pro del laicismo escolar, consistió en la promoción de ese tipo de escuelas para niños y adultos. Desde Orense, con la escuela laica neutral, a Tenerife con la escuela de la logia Añaza, desde Barcelona a Tánger, algunos talleres fueron creando centros docentes que se integraron en esa peculiar y alternativa red educativa. Quizá el momento y el lugar en que el compromiso escolar laicista de los masones en su vertiente práctica, alcanzó cotas más elevadas, fue en Cataluña, durante las dos últimas décadas del siglo $\mathrm{XIX}^{11}$. No debe extrañarnos. En aquellos años, tanto el movimiento de escuelas laicas como la masonería gozaron de buena salud en aquellas tierras. En ocasiones, dichas escuelas dependieron en exclusiva de los establecimientos masónicos. En otros casos, los masones de determinados lugares sumaron su esfuerzo al de otros grupos con idénticas inquietudes.

El interés resultó tan intenso que, en ocasiones, las logias llegaron a fundar entidades específicas para potenciar la implantación de esas escuelas. Una de las de mayor trascendencia fue la Sociedad Catalana de Amigos de la Enseñanza, creada en Barcelona en

radicalizada de la doctrina oficial de la Iglesia, subiendo algo el grado de rotunda condena de las instituciones masónicas.

${ }^{11}$ Pere Sánchez Ferré, La maçoneria en la societat catalana del segle XX. 1900-1947 (Barcelona: edicions 62, collecció estudis i documents, 1993). 
1880 para coordinar las actividades de nueve escuelas laicas sostenidas por logias catalanas adscritas al Gran Oriente de España. ${ }^{12}$

Otro momento de auge en la actividad masónica fue durante la II República, en la década de 1930. Al respecto cabe señalar que en 1933, al socaire del debate social y parlamentario sobre la ley de congregaciones religiosas, se promovió desde el Grande Oriente Español la creación de la Liga de Educación y Enseñanza (LEYE). En concreto, impulsó su creación la Gran Logia del Centro. Con ella, los masones intentaron emular a la Liga de Enseñanza fundada por Macé en Francia, aunque la influencia de la Liga española resultó infinitamente menor que la francesa ${ }^{13}$.

Otro dato a tener muy en cuenta es que en este periodo, que ha sido considerado por los especialistas como una etapa especialmente brillante de la masonería, los trescientos talleres masónicos que existían en el país y sus cerca de cinco mil masones sólo mantenían, de acuerdo con los últimos estudios publicados, los siguientes centros educativos: La escuela laica neutral de Orense, apoyada por la logia Constancia no. 13 en unión de otras entidades no masónicas; la Sociedad Benéfica Cultural Renovación en Madrid, financiada por varias logias y que atendía a 40 niños y niñas y que pasó por serios apuros económicos en esos años; la escuela neutra de Gijón y la ya citada escuela la de logia tinerfeña Añaza, que, según la documentación localizada, atendía en 1931 a 14 niños y en 1935 a 30. También hay datos muy escasos e inconcretos que hablan de un Colegio Academia Cervantes impulsado por la logia Delta en Barcelona en 1936.

Ahora bien, si las entidades educativas sustentadas por logias no fueron demasiadas, podemos contabilizar bastantes más propuestas para crearlas, debatidas y aprobadas en tenidas y asambleas masónicas, pero que nunca fueron llevadas a la práctica. Ese abultado número de proyectos nonatos nos marca con meridiana claridad la gran distancia existente entre el discurso y la realidad de la masonería española de aquellos años. Lo que se encuentra perfectamente documentado es que durante la II República, la masonería sostenía cinco escuelas, sino cuatro, todas ellas unitarias y que en su conjunto no llegaba a escolarizar ni siquiera un centenar de alumnos. En nuestra opinión, no parece un balance especialmente exitoso ${ }^{14}$.

Además, no debemos de perder de vista la perspectiva general. El bloque laicista español se nutrió de muy variados grupos, entre los cuales los masones no destacaron ni por su número ni por sus aportaciones. Un ejemplo concreto lo localizamos en las escuelas laicas que funcionaron en la ciudad de Valencia durante el primer tercio del siglo XX. Allí existió una red bastante potente vinculada al partido blasquista, integrada por una decena de

\footnotetext{
${ }^{12}$ Sánchez Ferré, La maçoneria en la societat catalana, 131-140.

${ }^{13}$ Cruz, Masonería y educación en la II República, 148-153.

${ }^{14}$ Cruz, "Laicismo escolar, anticlericalismo y masonería en la España contemporánea. Datos para una reflexión", en Masonería y Religión: Convergencias, Oposición ¿Incompatibilidad?, ed. Ferrer Benimeli (Madrid: Complutense, 1996), 253-269 y Cruz, Masonería y educación en la II República, 148-153.
} 
escuelas cuyo vértice se situaba en la escuela graduada de la Casa de la Democracia, ubicada en la sede principal del partido blasquista la ciudad. ${ }^{15}$ Frente a esa importante realidad, las logias valencianas solo intentaron organizar una institución cultural, proyecto que como tantos otros no acabó de concretarse y que no pasó del plano de las ideas al de las realidades tangibles.

Desde la perspectiva nacional, aunque como ya se señaló, resulta muy complicado ofrecer datos finales -la precariedad fue una de las características de estas instituciones- los especialistas han cifrado en unas 160, las existentes en aquellos años, de las cuales solo una escasa media docena podemos documentar fehacientemente su vinculación con entidades masónicas $^{16}$.

Por todo ello, y a modo de conclusión, podemos señalar que el esfuerzo de la masonería en el ámbito concreto de la creación y sostenimiento de escuelas laicas y de entidades de coordinación no debe minusvalorarse, aunque tampoco cabe engrandecerlo. Las logias constituyeron un sector más dentro de la vertiente educativa del movimiento laicista español. Pero, de acuerdo con las aportaciones de los especialistas, los grupos republicanos, socialistas y libertarios, tuvieron bastante mayor protagonismo que los talleres masónicos en los debates ideológicos y, sobre todo, en las tareas de creación y sostenimiento de las escuelas laicas.

\section{Bibliografía}

Cortijo, Esteban. "Fernando Valera Aparicio: Teósofo, masón y republicano". En La masonería en la España del siglo XX. Editado por José Antonio Ferrer Benimeli. Toledo: Universidad de Castilla-La Mancha y Cortes de Castilla-La Mancha, 1996.

Canal, Jordi. "Las campañas antisectarias de Juan Tusquets (1827-1939): Una aproximación a los orígenes del contubernio judeo-masónico-comunista en España". En La masonería en la España del siglo XX. Editado por José Antonio Ferrer Benimeli. Toledo: Universidad de Castilla-La Mancha y Cortes de Castilla-La Mancha, 1996.

Cruz, José Ignacio. "Laicismo escolar, anticlericalismo y masonería en la España contemporánea. Datos para una reflexión”. En Masonería y Religión: Convergencias, Oposición ¿Incompatibilidad? Editado por José Antonio Ferrer Benimeli. Madrid: Universidad Complutense, 1996.

Cruz, José Ignacio. "Lo que nos contaron, lo que sabemos y lo que nos queda por conocer. Masonería y educación en la España contemporánea”. En La masonería española en el

\footnotetext{
${ }^{15}$ Luis Miguel Lázaro Lorente, Las escuelas racionalistas en el País Valenciano (1906-1931) (València: NAU llibres, 1992).

${ }_{16}$ Algunas cifras, aproximadas, puede consultarse en Alejandro Tiana Ferrer, "Movimiento obrero y educación popular en la España contemporánea", Historia Social 27 (1997): 127-144.
} 
2000. Una revisión histórica. Editado por José Antonio Ferrer Benimeli. Zaragoza: Centro de Estudios Históricos de la Masonería Española, 2001.

Cruz, José Ignacio. Masonería y educación en la II República Española. Alicante: Instituto de Cultura "Juan Gil Albert", 1993.

Cruz, José Ignacio. "Masonería española en el XX. Entre el mito y la realidad". En Masonería e Ilustración. Del siglo de las luces a la actualidad. Editado por José Ignacio Cruz. Valencia: Publicacions de la Universitat de València, 2011.

Espigado Tocino, M. Gloria. "El analfabetismo en España. Un estudio a través del censo de población de 1877". Trocadero: Revista de historia moderna y contemporánea 2 (1990): 173-192.

Ferrer Benimeli, José Antonio coord. Índices de actas, de los Symposia Internacionales de Historia de la Masonería Española. Zaragoza: Centro de Estudios Históricos de la Masonería Española, 2009.

Ferrer Benimeli, José Antonio. La masonería española. Madrid: Itsmo, 1996.

Gabriel, Narciso de. "Alfabetización y escolarización en España (1887-1950)". En Revista de Educación 314 (1997): 217-243.

Grande Oriente Español. Constitución del Grande Oriente Español. Sevilla, Tipografía Minerva, s.a.

Lázaro Lorente, Luis Miguel. Las escuelas racionalistas en el País Valenciano (19061931). València: NAU llibres, 1992.

Sánchez Ferré, Pere. La maçoneria en la societat catalana del segle XX. 1900-1947. Barcelona: edicions 62, collecció estudis i documents, 1993.

Tiana Ferrer, Alejandro. "Movimiento obrero y educación popular en la España contemporánea”. En Historia Social 27 (1997): 127-144.

Tusquets, Juan. "Influencia sectaria en las escuelas". En Cuestiones actuales de Pedagogía. Madrid: Gráfica HALAR, 1934.

Valera, Fernando. "Apuntes para contestar a un cuestionario de don Aquilino González, en preparación de un trabajo periodístico sobre la masonería en España". Documento mecanografiado. Archivo particular.

Valera, Fernando. Misión de la Francmasonería en la reconstrucción de la Democracia Española. Conferencia pronunciada en la Gran Logia de la Argentina. Buenos Aires: Símbolo, 1962.

Viñao, Antonio. Escuela para todos. Educación y modernidad en la España del siglo XX. Madrid: Marcial Pons. 2004. 